\title{
Accelerated idioventricular rhythm observed under total intravenous anesthesia using remifentanil, propofol, and rocuronium
}

\author{
Mika Nakanishi, , Kaoru Masumo, Takako Oota, Takeshi Kato and Toshihiro Imanishi
}

\begin{abstract}
Accelerated idioventricular rhythm (AIVR) during anesthesia has been described in several drug toxicity such as from cocaine, halothane, desflurane, and propofol. We present the case of a man who developed episodes of AIVR observed under total intravenous anesthesia (TIVA) using remifentanil, propofol, and rocuronium. AIVR during anesthesia was a benign phenomenon, and further examinations after surgery showed no structural heart disease and the daily occurrence of idioventricular arrhythmias. This case suggests that the suppression of sinus and atrioventricular nodal function and the autonomic imbalance caused by propofol and remifentanil may induce AIVR with greater frequency.
\end{abstract}

Keywords: Accelerated idioventricular rhythm; Total intravenous anesthesia; Remifentanil; Propofol

\section{Background}

Accelerated idioventricular rhythm (AIVR) is a ventricular rhythm comprising three or more consecutive monomorphic beats, with a gradual onset. The discharge rate of the ectopic focus is similar to the sinus rate and between 50 and $120 \mathrm{bpm}$ (isorhythmic). The ectopic focus manifests when the sinus rate slows down (below that of the ectopic focus) or when the ectopic focus accelerates above its intrinsic rate by $30-40 \mathrm{bpm}$ [1]. Nine clinical features are helpful in distinguishing AIVR from ventricular tachycardia (VT): chance discovery; no symptoms; no hemodynamic effects; $<10 \%$ of sinus isochronicity; $\mathrm{HR}<120 \mathrm{bpm}$; simple conversion to sinus rhythm; short bursts; no effective drug treatment; and left bundle branch block [2].

AIVR during anesthesia has been described in several drug toxic cases such as from cocaine [3], halothane [4], desflurane [5], and propofol [6]. It might be caused by an electrolyte imbalance, post-resuscitation status after acute myocardial infarction, cardiomyopathy, or arrhythmogenic right ventricular dysplasia (ARVD) during the perioperative period [1]. We report a case of AIVR observed under total intravenous anesthesia using remifentanil, propofol, and rocuronium.

\footnotetext{
* Correspondence: mikadairisa@gmail.com

Department of Anesthesia, Osakafu Saiseikai Noe Hospital, Fruichi 1-3-25, Joto-ku, Osaka City, Osaka, Japan
}

\section{Case presentation}

A 50-year-old man, weighing $74 \mathrm{~kg}$, was scheduled for arthroscopic meniscectomy for a right meniscus injury. He had undergone the same surgery on the other side 1 year prior. The previous general anesthesia was induced with sevoflurane $4 \%$, propofol $140 \mathrm{mg}$, fentanil $50 \mu$ g, lidocaine $50 \mathrm{mg}$, and rocuronium $50 \mathrm{mg}$. Propofol $2-3 \mathrm{mg} / \mathrm{kg} / \mathrm{h}$, remifentanil $0.1-0.18 \mu \mathrm{g} / \mathrm{kg} / \mathrm{min}$, and sevoflurane $1 \%$ were maintained. His heart rate (HR) was 40-55 bpm. Atropine $0.5 \mathrm{mg}$ administered intravenously did not increase his HR over $55 \mathrm{bpm}$. Idioventricular rhythm or anesthetic complication was not observed. In this time a preoperative examination revealed no sign or symptom of cardiovascular disease and he was classified as an American Society of Anesthesiologists' (ASA) Physical Status Classification 1. A preoperative electrocardiogram (ECG) showed a sinus rhythm of $57 \mathrm{bpm}$, a QRS duration of $0.11 \mathrm{~s}$, and no ventricular ectopic beat (Fig. 1).

Before anesthetic induction without premedication, the patient's arterial blood pressure (BP) was $142 / 83 \mathrm{mmHg}$ and his HR was $48 \mathrm{bpm}$. General anesthesia was induced with propofol $180 \mathrm{mg}$, remifentanil $0.1 \mu \mathrm{g} / \mathrm{kg} / \mathrm{min}$, and rocuronium $30 \mathrm{mg}$. After laryngeal mask insertion, atropine $0.5 \mathrm{mg}$ was administered because his HR fell to $38 \mathrm{bpm}$ with a sinus rhythm. Nevertheless, despite the administration of atropine $0.5 \mathrm{mg}$ twice, his HR did not increase over 


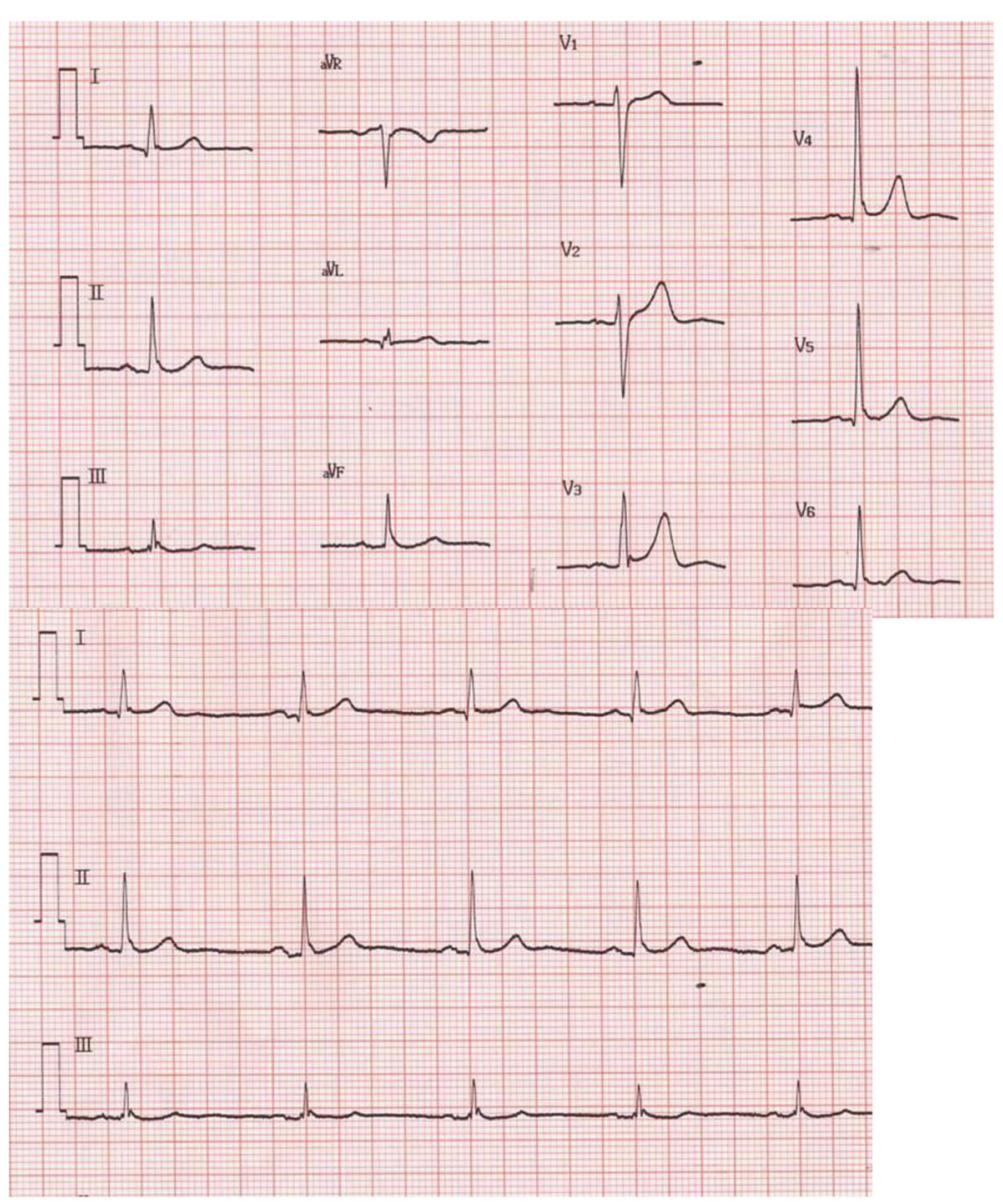

Fig. 1 Preoperative record of a 12-lead electrocardiogram, showing a sinus rhythm of 57 bpm

$55 \mathrm{bpm}$. Propofol 4-5 mg/kg/h, remifentanil 0.1-0.2 $\mu \mathrm{g} /$ $\mathrm{kg} / \mathrm{min}$, and rocuronium $7 \mu \mathrm{g} / \mathrm{kg} / \mathrm{min}$ were continued. His systolic BP was 90-140 mmHg, HR was 35-55 bpm, endtidal $\mathrm{CO}_{2}$ was $35-40 \mathrm{mmHg}$, and $\mathrm{SpO}_{2}$ was $99-100 \%$. About $30 \mathrm{~min}$ after induction, ventricular arrhythmia occurred with wide QRS complexes indicative of AIVR (ventricular rhythm at this time was $48 \mathrm{bpm}$ ) alternating with a sinus rhythm. Ventricular arrhythmia repeated approximately every $5 \mathrm{~min}$ for approximately $1 \mathrm{~h}$ and AIVRs continued for approximately $30 \mathrm{~s}$ (Fig. 2). Heart rates of the idioventricular rhythms $(45-50 \mathrm{bpm})$ were similar to those of the sinus rhythms at those times. The arrhythmias were independent of electric cautery and surgical procedure. Propofol, remifentanil, and rocuronium were regulated with the rate of administration mentioned above in proportion to the surgical stress. Although direct arterial sphygmomanometry in his left radial artery showed that his systolic BP was 20-30 mmHg lower during AIVRs than during sinus rhythms, his systolic BP was kept 100-120 mmHg during ventricular arrhythmia. Blood gas analyses showed plasma sodium, potassium, calcium, glucose, $\mathrm{CO}_{2}, \mathrm{O}_{2}$, and $\mathrm{pH}$ values within normal ranges. Although temporary transcutaneous pacing pads combined with a defibrillator were prepared, they were not utilized. His stable hemodynamics and short bursts of arrhythmia did not need them. The anesthetic duration was $2 \mathrm{~h} 32 \mathrm{~min}$. The last AIVR just appeared when the surgery and administration of the anesthetics were finished. AIVR did not reappear after recovery from anesthesia.

During the following 24-h period, continuous ECG monitoring showed no ventricular rhythm, but sinus bradycardia at $35-50 \mathrm{bpm}$. He confessed that arrhythmia had been noted in periodical health examinations of the school and the company with no subjective symptoms and he had refused detailed examinations. Echocardiography performed 2 days later showed a normal cardiac structure. A Holter ECG 5 days after surgery showed sinus rhythms from 36-97 bpm and total rates of $0.69 \%$ premature atrial contraction (PAC) and $6.35 \%$ premature ventricular contraction (PVC), including an idioventricular rhythm running for 40 beats continuously. He 


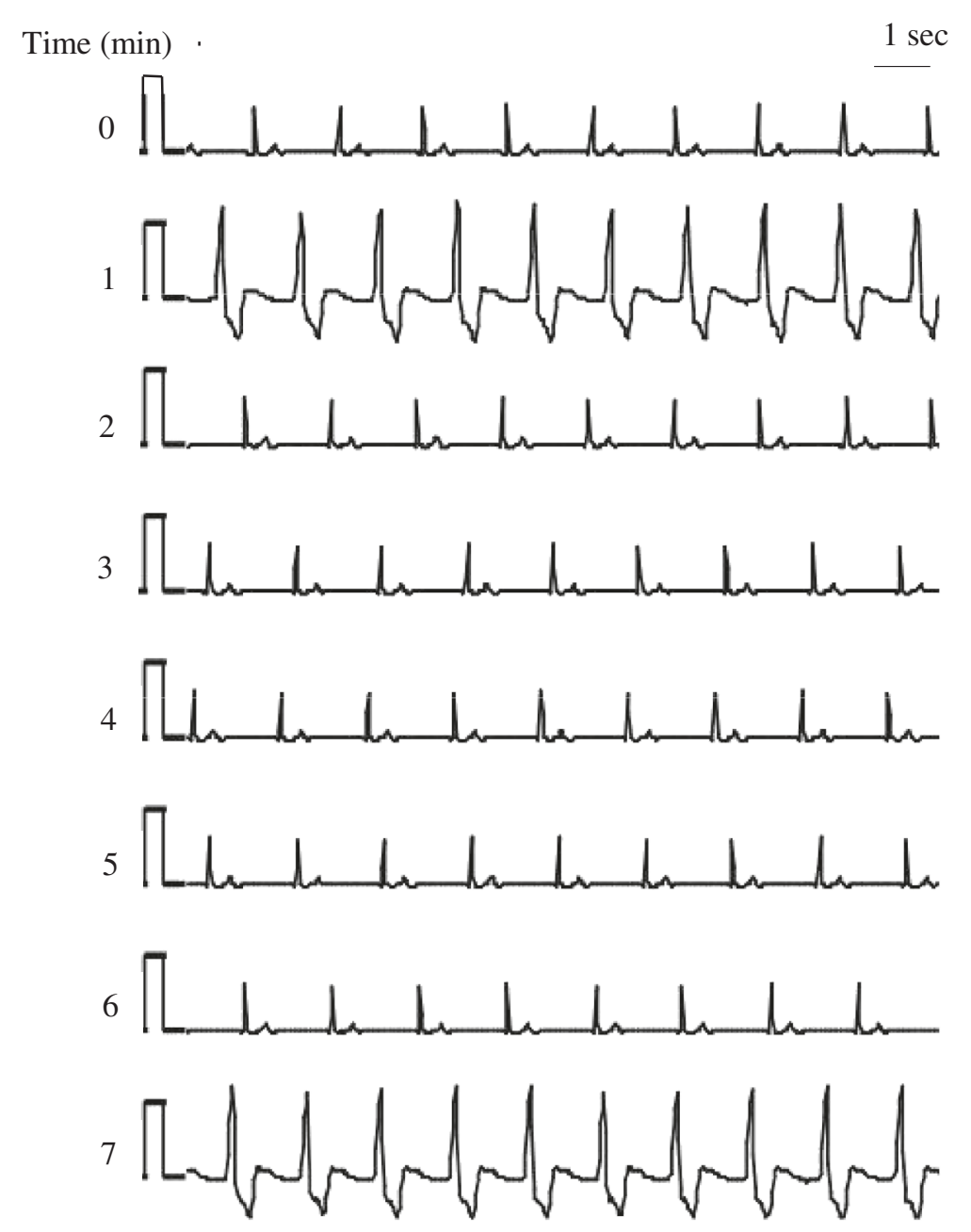

Fig. 2 Intraoperative electrocardiogram of III lead approximately 90 min after the anesthesia start under TIVA, documenting AIVRs alternating with sinus rhythms. Ventricular arrhythmia repeated approximately every $5 \mathrm{~min}$ and AIVRs continued for approximately $30 \mathrm{~s}$

did not have any subjective symptoms during the Holter ECG recording. The results suggested that his AIVR might have occurred daily. He refused further examinations.

\section{Discussion}

Atrioventricular (AV) junctional rhythm, another consecutive escaped rhythm, usually has a normal QRS duration without a $\mathrm{P}$ wave or with a retrograde $\mathrm{P}$ wave. If complicated with a bundle branch block, the QRS duration gets longer. AV junctional rhythm might lack effective atrial contraction and reduce the cardiac output than sinus rhythm, because atrial contraction contributes to approximately 15 to $25 \%$ of the diastolic filling of the ventricle [7]. AIVR originates from the His, the Purkinje system or the working contractile ventricular cells [1]. Ventricular pacing has been shown to result in dyssynchronous left ventricular (LV) electrical activation and mechanical contraction, to worsen LV ejection fraction [8]. AIVR is not artificial ventricular pacing, but its abnormal impulse conducting pathway might cause dyssynchronous LV contraction.

Some anesthetics have been described to be associated with AIVR because of toxicity. Cocaine might induce AIVR either through the production of myocardial ischemia or as a direct result of ion channel alterations $[3,9]$. Halothane was reported to be associated with AIVR due to a depressant effect on slow inward calcium current and intracellular calcium accumulation [4]. Desflurane was also reported to induce AIVR because of a sympathetic imbalance [5]. Propofol was publicized to be associated with arrhythmias in humans [10]. In the guinea pig heart, the ionic mechanism underlying the negative chronotropic action of propofol on sinoatrial node ( $\mathrm{SN}$ ) automaticity was associated with propofolinduced bradycardia observed in clinical settings [11]. Similar to propofol, remifentanil also depresses sinus 
node function and most parameters of atrioventricular (AV) nodal function, causing remifentanil-related severe bradyarrhythmias [12]. In this case, the negative chronotropic action of propofol and remifentanil on sinus and AV nodal function might have induced the ectopic focus more often than usual.

AIVR is also associated with higher vagal tone and lower sympathetic activity [13], and the AIVR related to sympathetic nerve block during spinal anesthesia for cesarean section was reported [14]. Propofol suppresses both sympathetic and parasympathetic tone, but the suppression of sympathetic tone is more than that of parasympathetic tone [15]. Remifentanil also induces higher vagal tone [16]. In this case, superior vagal tone related to propofol and remifentanil might have induced AIVR. However, ventricular rhythm was not detected during the postoperative $24-\mathrm{h}$ period including his sleeping hours, time of the parasympathetic nerve predominance. We did not succeed in clarifying the trigger of the idioventricular rhythm observed in the Holter ECG, but his activity at the time of the record was higher than that at the postoperative 24-h period. Not parasympathetic nerve predominance during sleep but imbalance of the autonomic nerve caused by anesthetics might have induced AIVR more frequently.

Naranjo algorithm is a questionnaire designed by Naranjo et al. for determining the likelihood of whether an adverse drug reaction is actually due to the drug rather than the result of other factors [17]. Probability is assigned via a score termed definite (9-13 points), probable (5-8 points), possible (1-4 points) or doubtful ( 0 point). On using Naranjo's scale, we obtained a scale of 5, which makes propofol and remifentanil probable causes for the event. The adverse event appeared after their administration $(+2)$. The adverse event improved when they were discontinued $(+1)$. The reaction was less severe when their doses were decreased $(+1)$, because the surgery 1 year prior had no episode of an AIVR with balanced anesthesia using sevoflurane, remifentanil, and propofol, the doses of which were lower than those at this time. The arrhythmias were objectively recorded on an ECG trace $(+1)$.

Most AIVRs are usually well tolerated and do not need specific treatment. Increasing the sinus rate is the recommended treatment for AIVR, therefore, atropine and atrial pacing rhythm can help to control it $[1,2]$. Ephedrine is controversial because it can potentially increase AIVR duration [14].

Benign AIVRs with no structural heart disease and no electrolytic abnormality, such as in this case, usually require no intervention. However, sometimes it can present as a more severe arrhythmia requiring treatment, because AIVR might be induced by reperfusion after acute myocardial infarction, some cardiomyopathies, myocarditis, and in newborn infants with various congenital heart diseases $[1,2]$.

\section{Conclusions}

We observed AIVR under total intravenous anesthesia using remifentanil, propofol, and rocuronium. The suppression of sinus and atrioventricular nodal function and the autonomic imbalance caused by remifentanil and propofol might have induced AIVR with greater frequency.

\section{Consent}

The patient's consent to publish this case report was obtained and documented.

\section{Competing interests}

The authors declare that they have no competing interests.

\section{Authors' contributions}

$\mathrm{MN} ;$ I anesthetized and examined him after surgery. I wrote this report. KM; She examined him in preoperation. TO; She examined him in preoperation 1 year prior. TK; He anesthetized him this time and 1 year prior. Tl; He examined him in preoperation this time and 1 year prior. All authors read and approved the final manuscript.

Received: 14 July 2015 Accepted: 1 September 2015

Published online: 07 September 2015

\section{References}

1. Riera AR, Barros RB, de Sousa FD, Baranchuk A. Accelerated idioventricular rhythm: history and chronology of the main discoveries. Indian Pacing Electrophysiol J. 2010;10:40-8.

2. Reynolds JL, Pickoff AS. Accelerated ventricular rhythm in children: a review and report of a case with congenital heart disease. Pediatr Cardiol. 2001;22:23-8.

3. Jonsson S, O'Meara M, Young JB. Acute cocaine poisoning. Importance of treating seizures and acidosis. Am J Med. 1983;75:106-14.

4. Chhabra A, Subramaniam R. Sudden appearance of idioventricular rhythm during inhalational induction with halothane in a child with congenital cataract. J Postgrad Med. 2008;54:337-9.

5. Marret $E_{1}$ Pruszkowski O, Deleuze A, Bonnet F. Accelerated idioventricular rhythm associated with desflurane administration. Anesth Analg. 2002;95:319-21.

6. Scruggs SM, Mama K, Bright JM, Zirofsky D. Accelerated idioventricular rhythm following propofol induction in a dog undergoing ocular surgery. Vet Anaesth Analg. 2010;37:385-6.

7. Healey JS, Toff WD, Lamas GA, Andersen HR, Thorpe KE, Ellenbogen KA, et al. Cardiovascular outcomes with atrial-based pacing compared with ventricular pacing: meta-analysis of randomized trials, using individual patient data. Circulation. 2006;114:11-7.

8. Sweeney MO, Hellkamp AS, Ellenbogen KA, Greenspon AJ, Freedman RA, Lee $K L$, et al. Adverse effect of ventricular pacing on heart failure and atrial fibrillation among patients with normal baseline QRS duration in a clinical trial of pacemaker therapy for sinus node dysfunction. Circulation. 2003;107:2932-7.

9. Wood DM, Dargan PI, Hoffman RS. Management of cocaine-induced cardiac arrhythmias due to cardiac ion channel dysfunction. Clin Toxicol. 2009;47:14-23.

10. Muńoz R, Goldberg ME, Cantillo L, Subramoni J, Nemiroff MS. Perioperative arrhythmias with a propofol-based anesthetics. J Clin Anesth. 1991;3:149-52.

11. Kojima A, Ito $Y$, Kitagawa $H$, Matsuura $H$. lonic mechanisms underlying the negative chronotropic action of propofol on sinoatrial node automaticity in guinea pig heart. Br J Pharmacol. 2015;172:799-814.

12. Zaballos M, Jimeno C, Almendral J, Atienza F, Patiño D, Valdes E, et al. Cardiac electrophysiological effects of remifentanil: study in a close-chest porcine model. Br J Anaesth. 2009;103:191-8. 
13. Bonnemeier H, Ortak J, Wiegand UK, Eberhardt F, Bode F, Schunkert H, et al. Accelerated idioventricular rhythm in the post-thrombolytic era: incidence, prognostic implications, and modulating mechanisms after direct percutaneous coronary intervention. Ann Noninvasive Electrocardiol. 2005;10:179-87.

14. Coven G, Arpesella R, Ciceri M, Preseglio I, Cardani A. Accelerated idioventricular rhythm during spinal anesthesia for cesarean section. Int J Obstet Anesth. 2003;12:121-5.

15. Liu Q, Kong AL, Chen R, Qian C, Liu SW, Sun BG, et al. Propofol and arrhythmias: two sides of the coin. Acta Pharmacol Sin. 2011;32:817-23.

16. Fattorini F, Romano R, Ciccaglioni A, Pascarella MA, Rocco A, Mariani V, et al. Effects of remifentanil on human heart electrical system. A transesophageal pacing electrophysiological study. Minerva Anestesiol. 2003;69:673-9.

17. Naranjo CA, Busto U, Sellers EM, Sandor P, Ruiz I, Roberts EA, et al. A method for estimating the probability of adverse drug reactions. Clin Pharmacol Ther. 1981;30:239-45.

\section{Submit your manuscript to a SpringerOpen ${ }^{\circ}$ journal and benefit from:}

- Convenient online submission

- Rigorous peer review

- Immediate publication on acceptance

- Open access: articles freely available online

- High visibility within the field

- Retaining the copyright to your article 